\title{
Modified C-17 taxi procedures: a fuel cost savings exploration
}

\author{
Michael Wells
}

Department of Operational Sciences, Graduate School of Engineering and Management, Air Force Institute of Technology, Wright-Patterson AFB, Ohio, USA

Michael Kretser

Calhoun Discovery Program, Honors College, Virginia Polytechnic Institute and State University, Blacksburg, Virginia, USA

Ben Hazen

Department of Logistikum, Faculty of Management, University of Applied Sciences Upper Austria, Steyr, Austria, and

\section{Jeffery Weir}

Department of Operational Sciences, Graduate School of Engineering and Management, Air Force Institute of Technology, Wright-Patterson AFB, Ohio, USA

\begin{abstract}
Purpose - This study aims to explore the viability of using C-17 reduced-engine taxi procedures from a cost savings and capability perspective.

Design/methodology/approach - This study model expected engine fuel flow based on the number of operational engines, aircraft gross weight (GW) and average aircraft groundspeed. Using this model, the research executes a cost savings simulation estimating the expected annual savings produced by the proposed taxi methodology. Operational and safety risks are also considered.

Findings - The results indicate that significant fuel and costs savings are available via the employment of reduced-engine taxi procedures. On an annual basis, the mobility air force has the capacity to save approximately 1.18 million gallons of jet fuel per year (\$2.66m in annual fuel costs at current rates) without significant risk to operations. The two-engine taxi methodology has the ability to generate capable taxi thrust for a maximum GW C-17 with nearly zero risks.

Research limitations/implications - This research was limited to C-17 procedures and efficiency improvements specifically, although it suggests that other military aircraft could benefit from these findings as is evident in the commercial airline industry.

Practical implications - This research recommends coordination with the original equipment manufacturer to rework checklists and flight manuals, development of a fleet-wide training program and evaluation of future aircraft recapitalization requirements intended to exploit and maximize aircraft surface operation savings.
\end{abstract}

Originality/value - If implemented, the proposed changes would benefit the society as government resources could be spent elsewhere and the impact on the environment would be reduced. This research

(C) In accordance with section 105 of the US Copyright Act, this work has been produced by a US government employee and shall be considered a public domain work, as copyright protection is not available. Published in Journal of Defense Analytics and Logistics. Published by Emerald Publishing Limited. 
JDAL 4,2

conducted a rigorous analysis of the suitability of implementing a civilian airline's best practice into US Air Force operations.

Keywords Air transportation, Simulation, Aircraft procedures, Cost savings, Fuel savings, Least-squares regression

Paper type Research paper

\section{Introduction}

Energy is critical to the security and welfare of our nation. As the largest user of petroleum in the world (Schwartz et al., 2012), the Department of Defense (DoD) must continue to explore methods to reduce its reliance on energy resources. It is the author's professional opinion that the DoD's global presence creates a lengthy logistical tail requiring sustained, worldwide mobility of people and resources. Dependence on the shared logistical necessities required to support national priorities and global operations places the nation at financial, operational and strategic risk. In an environment of limited and diminishing resources, the accessibility of energy will directly impact our nation's capability to perform its operational mission and provide for the common defense. As such, air force fuel savings are of utmost importance as energy sources decrease. Because of the magnitude of costs associated with operating mobility aircraft in a fiscally constrained environment, Air Mobility Command (AMC) must streamline its practices, optimize fuel usage and decrease costs.

In his "sustaining US global leadership: priorities for the 21st Century Defense" Directive, President Barack Obama mandated reductions in defense spending (Dept of Defense, 2012). Similarly, Secretary of Defense Robert Gates directed the military services to reduce their monetary footprints. One of Secretary Gates' primary emphasis items was to reduce fuel and energy consumption within the US Air Force's (USAF's) AMC. In this mandate, Secretary Gates required the USAF to develop a plan to reduce the mobility aircraft's fuel usage by $\$ 700 \mathrm{~m}$ from the fiscal year 2012 to 2016 (Brown, 2011). The target was an $8.75 \%$ reduction goal as the air force spent $\$ 8.3 \mathrm{bn}$ on fuel in the fiscal year 2011.

To comply with this aggressive demand, the USAF developed distinct energy priorities improve resiliency, reduce demand, assure supply and foster an energy-aware culture (Donley and Welsh, 2013). AMC translated this directive into a comprehensive evaluation of its mobility mission. Specifically, the program reviewed aircraft maintenance and modernization, aircraft loading procedures, flight plan routing, flight scheduling and operational mission execution (Joyner, 2011). To further investigate capacities for potential fuel conservation, the USAF reviewed and analyzed the commercial aviation industry, which boasted a $5 \%$ fuel reduction in fuel consumption from 2000 to 2006 while increasing their passenger movement by $12 \%$ and their cargo movement by $22 \%$ (Joyner, 2011). Today, researchers continue to evaluate margins for operational fuel efficiencies within the aviation community.

Commercial airlines often conserve fuel by taxiing on only the number of engines required to produce capable taxi thrust. Exploring this comparatively better business practice used in the commercial airline industry might prove beneficial and drive efficiencies for the USAF. As the USAF continues to evaluate margins for monetary and energy savings, AMC should consider operational best practices that yield efficiencies without impacting effectiveness. When appropriate conditions exist, this taxiing strategy can decrease fuel usage and increase cost savings.

\section{Objective}

The purpose of this study is to explore the potential fuel savings and subsequent fiscal advantages gained by the $\mathrm{C}-17$ community adopting a practice of taxiing on a reduced 
number of engines prior to initial takeoff. The efficiency of this practice will be compared to the technical and operational risks associated with executing this maneuver. Specifically, this research seeks to answer the following questions:

Q1. On an annual basis, how much fuel can the mobility air force (MAF) save by implementing reduced-engine taxi procedures?

Q2. How do potential fuel savings from reduced-engine taxi procedures compare to the risks of engine-start malfunctions and subsequent back taxi maneuvers?

Modified C-17 taxi procedures

Q3. How does aircraft gross weight (GW) impact the reduced-engine taxi procedure's average thrust requirements to produce capable taxi thrust during lengthy periods of taxis?

\section{Literature background}

Over the past decade, financial limitations and energy constraints have forced AMC to fundamentally alter its energy awareness and operating practices. A Research and Development (RAND) study (Kennedy et al., 2006) investigation stated that "over the next 50 years, fuel reserves [will] continue to be depleted and as supplies diminish, prices will escalate and availability will become less certain both home and abroad." Given the anticipated fiscal and energy constraints facing the DoD, AMC has adopted and sustained fuel-savings initiatives.

Resource dependency theory recognizes the influence of external factors on organizational behavior (Hillman et al., 2009). According to this theory, organizations will strive to minimize uncertainty and dependence and maximize [their] autonomy (Davis and Cobb, 2010). This theory informs the research design by acknowledging that AMC should adapt its organizational behavior due to limitations of critical resources. The central proposition of the resource dependency theory stipulates that "organizations (or organizational sub-units) controlling resources that other actors need have power over these actors" (Nienhüser, 2008). This theory suggests that fuel providers will retain power over the DoD's behaviors due to the inextricable linkage between the $\mathrm{DoD}$ and its need for fuel. Given restricted maneuverability to acquire additional resources, AMC should continue to explore additional fuel-efficiency initiatives, thereby reducing its dependence on the limiting resource.

Literature shows that engineers are well-aware of alternates that provide opportunities for the USAF to yield better fuel savings and fuel efficiencies. The primary obstacle is to "[determine], which initiatives to implement and in what order, to maximize efficiency" (Brown, 2011). Tactical-level operations such as flight planning, optimizing fuel loads and reconfiguring cargo configurations have produced immediate and positive results (Brown, 2011). Another RAND study reveals the capacity for further fuel savings via more efficient ground and flight operations (Mouton et al., 2015). Mouton et al. (2015) highlight available fuel efficiencies and operational gains via reduced-engine taxiing procedures. This taxi strategy offers a solution for more efficient operations without adding significant risks to mission execution (Marais et al., 2013). The USAF has taken initial steps to make changes and has given pilots the freedom to adjust their engine startup procedures to reduce fuel usage, but none of these sources quantify the potential savings should these changes become institutionalized (Dept of the Air Force, 2011; Air Mobility Command, 2015). In 2016, the USAF Energy Analysis Task Force (USAF EATF) studied the current use, current barriers, possible benefits and potential savings of reduced engine taxiing from an administrative procedure approach. In their analysis, they recommend expanding pilot procedures to allow for and recommend reducing the number of engines required for different procedures with an estimated cost savings of between $\$ 2.3 \mathrm{~m}$ to as much as $\$ 5.6 \mathrm{~m}$ 
JDAL 4,2

(Secretary of the Air Force USAF EATF, 2016). In 2018, the USAF EATF conducted an analysis of C-17 operational efficiency and not only found procedural disincentives to increasing risk for late take-offs due to delayed engine starting but also found potential cost savings of $\$ 2.8 \mathrm{~m}$ to $\$ 6.9 \mathrm{~m}$ should procedural changes delay engine starting (vice running all four engines $30 \mathrm{~min}$ prior to scheduled take-off time) (EATF, 2018).

Commercial aircraft taxiing has recently been studied using flight data recorder data and researchers have built models to better predict fuel usage for the purpose of prescribing more efficient procedures for predicting fuel use and influencing pilot behavior and airline policy. Fuel usage and the accompanying pollutant output was studied in commercial aircraft at London's Heathrow Airport and the use of single-engine taxi during taxi-in was found to be the prescribed best practice to reduce both fuel used and pollution produced while not affecting the logistical flow of aircraft on the ground (Koudis et al., 2018). Taxi-out fuel burn was studied at Massachusetts Institute of Technology in 2011 and the most significant factors in estimating fuel burn were total taxi time and the number of acceleration events such as accelerating after a complete stop and "aggressive" pilot behavior (Khadilkar and Balakrishnan, 2011). Studying individual engine output was not studied.

The current research compliments the EATF efforts and provides academically rigorous prediction models to support their strategic goals of reducing energy use and money spent. This research assesses the risks and benefits of reduced engine taxi strategies.

\section{Method}

The Headquarters AMC Analysis, Assessments and Lessons Learned Directorate (AMC/A9) in coordination with the Operations Directorate (AMC/A3) provided the military flight operations quality assurance (MFOQA) data required to construct the models and simulation. To estimate the potential fuel savings that should exist from a reduced-engine taxi procedure, this research developed two linear least-squares regression models and one simulation using Microsoft Excel. The fuel-savings comparison model estimates the average fuel flow required for each operational engine during a taxi maneuver. Using engine data from 35 operational missions at four environmentally unique C-17 main operating bases (Charleston Air Force Base, SC; Ramstein Air Base, Germany; Travis Air Force Base, CA; and Joint Base Pearl Harbor-Hickam, $\mathrm{HI})$, the model calculates a representative sample of the potential fuel savings from the reducedengine taxi strategy across the comprehensive C-17 mission set.

Additionally, the research developed a simulation that approximated the fuel penalties caused by potential engine-start malfunctions during the delayed engine-start procedures. Delayed engine-start procedures are procedures taken after an engine fails to start the first time due to mechanical or environmental reasons; an engine will be restarted following another checklist. Using a Monte Carlo simulation executing 52,000 simulations (equal to the number of sorties flown for comparison), the study calculated the net annual impacts of the fuel and cost savings compared to the risks of engine-start malfunctions during the taxi maneuver. This simulation is used to determine if the energy and fiscal savings of the C-17 reduced engine taxi maneuver are sufficient to compensate for potential operational risks.

Finally, the optimal taxi policy prescribes either a four-engine or two-engine taxi strategy based on aircraft GW; symmetry is assumed to be important in maintaining control of the aircraft, so an odd number engine reduced-taxi model was not considered. The excessive jet blast was determined as a primary operational concern when considering a reduced-engine taxi methodology. The results of the optimal taxi policy model recommend guidelines for when pilots should use the reduced-engine taxi procedure as influenced by engine pressure ratio (the total pressure ratio across a jet engine) and aircraft $\mathrm{GW}$. 
Models

This research uses a model and simulation typology. This typology will derive two models (a fuel-savings comparison model and an optimal taxi policy model) using statistical leastsquares regression from operational data. Potential fuel savings for the reduced-engine taxi procedure were estimated via the development and execution of a cost savings simulation based on the derived fuel-savings comparison model. This simulation considered and applied a fuel consumption penalty for operational risk factors due to engine-start malfunctions. The optimal taxi policy model prescribed the use of either a four-engine or reduced-engine taxi methodology.

\section{Data overview}

To measure an aircraft's taxi characteristics and associated fuel consumption, historical MFOQA data was collected from headquarters AMC. Data samples were harvested from C-17 sorties originating at four unique main operating bases and translated into a Microsoft Excel spreadsheet for analysis. MFOQA data is similar to flight recorder data and allows AMC's director of operations to perform quality assurance assessments on pilots' flying behaviors. This data hub collects aircraft performance characteristics and parameters during various phases of aircraft operations. The data are used to analyze pilot flying behavior and create policies that result in safer and more efficient flying operations. For this research, the data allowed for the evaluation of performance characteristics during the taxi phase of operation, analysis of engine consumption characteristics given various fourengine and reduced-engine taxi methodologies, investigation of the impacts of aircraft taxi variables on engine pressure ratios and identification of margins for fuel efficiencies during surface operations.

Maintenance data from the Air Force G081 (aircraft mobility data systems) database maintained at the headquarters AMC logistics directorate (AMC/A4) are also used in this research. This data was used to determine the average percentage of C-17 engine-start malfunctions experienced per year. A detailed evaluation of the average percentage of engine-start malfunctions is critical to determining whether or not the operational risks of reduced-engine taxiing procedures outweigh the potential fuel savings. This information will be incorporated in the cost savings simulation and evaluate the entire concept of C-17 ground operations including operational risks. The experimental design incorporating this data resulted in approximated monetary savings resulting from the employment of the reduced-engine taxiing strategy.

Finally, historical data was used to determine the average number of C-17 sorties flown per year. This data was gleaned from a database maintained by AMC/A9. This data was used in the cost savings simulation and provided an estimate of annual cost savings. The simulation approximated annual fuel and cost savings, assuming future operation tempos are consistent with historical averages.

AMC/A9 in coordination with AMC/A3 provided 35 taxi data samples from four C-17 main operating bases. The extracted taxi data provided two distinct taxi types (outgoing and incoming taxi patterns) from aircraft taxiing with four and three operational engines. This data was filtered according to standardized taxi-in and taxi-out definitions. The MFOQA data were collected at $0.25 \mathrm{~s}$ intervals, capturing the following variables: fuel flows for engines one through four, engine pressure ratios for engines one through four, outside air temperature, aircraft $\mathrm{GW}$, taxi distance, taxi time and aircraft ground speed. The data set so included a "point of interest" variable defining specific points of operation based on aircraft configuration and location and a "weight on wheels" variable yielding either a "true" or "false" output dependent on if the aircraft was on the ground or airborne, respectively. 
JDAL 4,2

The taxi-in variable was derived from a C-17 operating limitation, which stipulates that taxi operations must occur at groundspeeds below 40 knots. For this study, taxi-in was defined as the first aircraft movement occurring at a groundspeed below 40 knots immediately following landing roll-out. The taxi-in phase of the operation was terminated upon arrival into parking as defined by a sustained groundspeed of zero knots at the conclusion of the data set. Taxi-out was defined as aircraft surface movement starting with the initial movement from the parking position and terminating upon entry to the runway. Runway entry was determined using the data's "point of interest" variable. For both definitions (taxi-in and taxi-out), intermittent stops along the route of the taxi were included as portions of the comprehensive taxi maneuver.

AMC/A4 maintains the Air Force G081 database, which tracks the health and maintenance of all C-17 aircraft in the USAF inventory. This data tracks C-17 performance metrics, aircraft employment and maintenance trends. AMC/A4 provided query results outlining all engine malfunctions for a one-year period. The number of engine-start malfunctions was extracted from this data and compared (using the methodology described below) to the number of engines starts accomplished across the fleet per year. This trend data revealed the average number of $\mathrm{C}$ - 17 engine-start malfunctions experienced per year across the fleet. This data allowed for the construction of a cost savings simulation, employment of an operational penalty of taxi costs when pilots experience engine-start malfunctions after initiation of the taxi maneuver and calculation of an annual monetary fuel savings approximation.

AMC/A9 maintains a database showcasing the number of sorties flown per year for each aircraft in the MAF fleet. AMC/A9 provided a single constant reflecting C-17 employment in terms of the number of sorties for the fiscal year 2016. This data allowed for the determination of the number of simulations required to calculate an approximation for the annual monetary savings available via the employment of the reduced-engine taxi strategy.

To understand engine efficiency characteristics, four variables are required, namely, aircraft GW, the thrust required to perform the taxi maneuver, the specific fuel consumption (SFC) and the overall engine fuel flow required to generate thrust to execute the taxi maneuver (McCollum, 2017). McCollum estimated the thrust required to taxi a C-17 aircraft by multiplying the aircraft's GW by the rolling coefficient of friction $\left(\mu_{r}\right)$. For this specific model, the rolling coefficient of friction is assumed to remain constant with a value of 0.02 .

$$
\text { Thrust Required }=(G W)\left(\mu_{r}\right)
$$

McCollum (2017) noted that the available thrust for a C-17 is approximately 1,700 lbs per engine at ground idle, approximately 3,400 lbs per engine at high idle and 10,000 lbs per engine at maximum continuous thrust. To calculate fuel flow per hour, McCollum suggested multiplying thrust required per engine by the number of operational engines by the SFC for the respective thrust requirements. The $\mathrm{SFC}$ values for the aforementioned power settings during taxi operations are 0.58, 0.41 and 0.33, respectively (McCollum, 2017).

$$
\text { Fuel flow }=(\text { Thrust Required })(\text { Number of Engines })(S F C)
$$

Given an aircraft with a GW of 340,000 lbs, equation (1) can be used to determine that it will take 6,800 lbs of thrust for pilots to execute the taxi maneuver. Dividing this value by four operational engines, it is determined that it will take $1,700 \mathrm{lbs}$ of thrust per engine to generate the required force to execute the maneuver. Inputting these values into equation (2), the determined expected fuel flow to taxi the aircraft with four engines is 3,944 lbs of fuel per hour. Accomplishing the same example using the reduced-engine taxi procedure (i.e. two 
engines operational), equation (1) reveals that it will take 3,400 lbs per engine to generate the required force to execute the taxi maneuver. Inputting these values into equation (2), the determined expected fuel flow to taxi the aircraft with two engines is $2,788 \mathrm{lbs}$ of fuel per hour. McCollum (2017) demonstrated using theoretical data that using the reduced-engine taxi procedure nets a savings of approximately 1,156 lbs of fuel per hour of a taxi.

The results of this rationalization model demonstrate that engines operating at higher thrust settings during surface operations operate more efficiently than engines operating at lower thrust settings. Therefore, it is better to use two engines than four engines to generate the required total thrust to execute the taxi maneuver. The engine's inherent efficiency characteristics demonstrate the innate benefits of using the reduced-engine taxi procedure.

\section{Data analysis and synthesis}

The analyzed data set included C-17 taxi characteristics and fuel consumption, engine-start malfunction trends and the average annual number of $\mathrm{C}-17$ sorties. The analysis and characterization of this data provided a comparison of reduced-engine taxi procedures to current four-engine taxi practices. The parameters for these models were calculated using measures of central tendency, linear least-squares regression and a Monte Carlo simulation.

\section{Fuel-savings comparison model}

The original model used multiple factors to predict average fuel flow per engine, but several were found to be insignificant, including average fuel consumed per operational engine, total taxi time in seconds, average outside air temperature in degrees celsius, total taxi distance in miles, average taxi groundspeed in knots, average aircraft GW in pounds during the taxi maneuver, number of inoperative engines during the taxi maneuver and binary variables defining an aircraft's operating location. Variables with $p$-values greater than 0.05 were discarded as statistically insignificant to the model; an $\alpha$ value of 0.05 was selected as it produced a simple model with a strong goodness-of-fit statistic. The resulting fuel flow model with significant predictors was simplified to:

$$
f=\beta_{4} r+\beta_{5} W+\beta_{6} E n g
$$

This model suggests aircraft ground speed $r$, aircraft gross weight $W$ and the number of inoperative engines Eng during the taxi maneuver are statistically significant predictors of the required average engine fuel flow per operational engine $f$ to execute the taxi maneuver.

Table 1 presents the results from the model's updated parameter estimations. The $R^{2}$ value for the resultant model is 0.9913 .

To validate the fuel savings model, the supplied data was compared to the model's approximated results. The model's average fuel flow per operational engine was calculated by inputting the average aircraft groundspeed, average aircraft GW and number of inoperative engines from the actual operational mission data into the model's simplified equation. The

\begin{tabular}{lcc}
\hline Parameter & Coefficient & $p$-value \\
\hline Weight $\left(\beta_{4}\right)$ & 0.002088 & $<0.001$ \\
Engines inoperative $\left(\beta_{5}\right)$ & 130.2207 & 0.01304 \\
Groundspeed $\left(\beta_{6}\right)$ & 18.5329 & 0.00061
\end{tabular}

Table 1.

Refined model outputs for parameter estimates of average engine fuel flow per operational engine 
JDAL 4,2

standard error between the model and the operational data results was determined by calculating the average of the absolute value of the difference between the approximated results to the operational four-engine data results and dividing by the operational results.

Because the MFOQA recorder does not generate data when less than three engines are operating on the aircraft, data for two-engine taxi scenarios could not be acquired. The fuel-savings comparison model was extrapolated to a two-engine scenario. The twoengine average fuel consumption per operational engine was calculated using operational data. The total average fuel flows per operational engine was multiplied by the total number of expected operational engines per the respective taxi methodologies. These results were compared to the operational four-engine average fuel consumption per engine data. The predicted two-engine total fuel flow approximations were subtracted from the operational average four-engine total fuel flow values and then averaged to find the mean of the total fuel flow differences for each data sample. The outcome of this model was an initial estimation of the total fuel savings available per sortie in pounds of fuel consumed per hour.

\section{Cost savings simulation}

The cost savings simulation determined if the energy and fiscal savings of the reduced-engine taxi maneuver in the $\mathrm{C}-17$ community are sufficient to compensate for the potential risks of engine-start malfunctions during the execution of the taxi maneuver. The fuel-savings comparison model was used to calculate the average fuel flows per operational engine for two sets of 52,000 data samples (the approximate total number of C-17 sorties flown in the fiscal year 2016). One set of 52,000 simulations approximated the average fuel flow per operational engine assuming employment of reduced-engine taxi procedures on $50 \%$ of $\mathrm{C}-17$ sorties and a $2 \%$ operational risk factor. For sorties experiencing operational risk, the taxi parameters were doubled to account for the anticipated return to parking from the furthest possible point of taxi (i.e. runway entry). The second set of 52,000 simulations approximated the average fuel flows per operational engine assuming pilots used only four-engine taxi procedures.

To simulate hypothetical taxi patterns and calculate fuel consumption results for fourengine and reduced-engine taxi procedures, random values were created for each of the fuelsaving model's variables. These values were assumed between the ranges of numbers based on data from the operational data set. The aircraft GW was assumed between 315,000 lbs and $585,000 \mathrm{lbs}$ to emulate aircraft capacity constraints. The aircraft groundspeed was assumed between 5 and 20 knots. Although not a variable within the fuel-savings comparison model, the total taxi time was included to yield an estimate for the amount of fuel saved in pounds. The total taxi time value was assumed between 30 and 1,000s. The results of the random variable inputs were multiplied by the number of operational engines depending on the assumed taxi methodology.

To determine the total cost savings provided by employment of the reduced-engine taxi procedure, the total amount of fuel (in pounds) estimated by the $50 \%$ reduced-engine taxi data set with a $2 \%$ operational risk factor was subtracted from the total amount of fuel (in pounds) estimated by the four-engine simulation set. This value was divided by $6.7 \mathrm{lbs}$ per gallon and then multiplied by the current price point of aviation jet fuel per gallon ( $\$ 2.26$ per gallon) published by the Defense Logistics Agency (DLA, 2017). The results for 52,000 simulations (the estimated annual number of C-17 sorties) were calculated in increments of 2,000 simulations. The resulting figure is the fiscal savings produced by reduced-engine taxi procedures. The net cost and fuel savings account for the potential risks of engine-start malfunctions during the execution of the taxi maneuver according to the $2 \%$ operational risk factor. 


\section{Optimal taxi policy model}

Finally, an optimal taxi policy was developed to prescribe either a four-engine or two-engine taxi strategy based on aircraft GW; symmetry is assumed to be important in maintaining control of the aircraft, so one and three-engine reduced-taxi model was not considered. During a literature review, an excessive jet blast was determined as the primary operational concern when considering a reduced-engine taxi methodology. The results of the optimal taxi policy model recommend guidelines for when pilots should use the reduced-engine taxi procedure as influenced by engine pressure ratio (the total pressure ratio across a jet engine) and aircraft GW.

Two engines have the capability to generate sufficient thrust at higher thrust settings to effectively maneuver a C-17 operating at maximum GW. However, to mitigate risk caused by the excessive jet blast, a maximum average value of 1.03 engine pressure ratio was selected as the optimized taxi-thrust setting. C-17 regulations stipulate that taxi operations must remain below 1.05 engine pressure ratio during taxi-in. If an engine exceeds 1.05 engine pressure ratio, then the engine must remain at an idle power setting for at least 3 min before engine shutdown to allow for sufficient engine cooling. The literature demonstrates that engines should have an appropriate warm-up period prior to nominal operations. As such, the maximum average value of 1.03 engine pressure ratio will serve as a guiding directive to maximize engine life and minimize engine overuse before it is sufficiently warmed.

The optimal taxi policy model approximated the average engine pressure ratio via linear least-squares regression analysis of seven independent variables. The average engine pressure ratio was modeled as follows:

$$
E P R=\propto_{1} t+\propto_{2} T_{O A T}+\propto_{3} d+\propto_{4} r+\propto_{5} W+\propto_{6} E n g+\propto_{7} F F+\propto_{8}
$$

where $E P R$ is the average engine pressure ratio, $t$ is the total taxi time in seconds, $T_{O A T}$ is the average outside air temperature in degrees celsius, $d$ is the total taxi distance in miles, $r$ is the average taxi groundspeed in knots, $W$ is the average aircraft $\mathrm{GW}$ in pounds during the taxi maneuver, Eng is the number of inoperative engines used during the taxi maneuver, FF is the average fuel flow per operational engine and $\alpha_{1}-\alpha_{8}$ are estimated parameters resulting from the least-squares regression calculation.

Table 2 presents the results from the model's initial parameter estimations. This table showcases the calculated coefficients and statistical significance of each respective value given the aggregate model. This model yielded an $R^{2}$ value of 0.811 .

Variables with $p$-values greater than 0.1 were discarded as statistically insignificant to the model. Schumacher (2015) studied C-17 fuel efficiency using goal-setting Theory and the highest predictable factor was adjusting cargo weights. As average aircraft $\mathrm{GW}$ is included in other models in this study and is a prominent factor in other aircraft studies concerning fuel usage, it was determined important enough and close enough to 0.1 to leave it in the resulting optimal taxi model.

\begin{tabular}{lcc}
\hline Parameter & Coefficient & $p$-value \\
\hline Time $\left(\alpha_{1}\right)$ & $4.9321 \mathrm{E}-06$ & 0.02269 \\
Temperature $\left(\alpha_{2}\right)$ & $-1.3328 \mathrm{E}-05$ & 0.57410 \\
Distance $\left(\alpha_{3}\right)$ & -0.001387 & 0.05948 \\
Groundspeed $\left(\alpha_{4}\right)$ & 0.0002790 & 0.00674 \\
Weight $\left(\alpha_{5}\right)$ & $6.4567 \mathrm{E}-09$ & 0.10820 \\
Inoperative engines $\left(\alpha_{6}\right)$ & 0.001040 & 0.06168 \\
Fuel flow $\left(\alpha_{7}\right)$ & $1.3072 \mathrm{E}-05$ & $<0.001$ \\
Intercept $\left(\alpha_{8}\right)$ & 0.9870 & $<0.001$
\end{tabular}

Modified C-17 taxi procedures

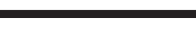


JDAL 4,2

Table 3.

Refined model outputs for parameter estimates of average engine pressure ratio
The resulting average engine pressure ratio model was simplified to:

$$
E P R=\propto_{1} t+\propto_{3} d+\propto_{4} r+\propto_{5} W+\propto_{6} E n g+\propto_{7} F F+\propto_{8} \text { eq }
$$

Table 3 presents the results from the model's updated parameter estimations. The resulting model yielded an $R^{2}$ value of 0.809 .

To validate the average engine pressure ratio model, operational data was compared to the model's approximated results. The model's average engine pressure ratio was calculated by inputting the operational average engine fuel flows, total taxi time, total taxi distance, aircraft ground speed, aircraft GW and number of inoperative engines from the operational data into the model's simplified equation.

To determine the optimal taxi policy model, an experimental design was created using the two derived models (the average fuel flow per operational engine model and the average engine pressure ratio per operational engine model). Because the optimal taxi policy prescribes either a four-engine or two-engine taxi strategy based on aircraft $\mathrm{GW}$, the experiment was designed to output average engine pressure ratios per operational engine for aircraft GWs starting at $285,000 \mathrm{lbs}$ and terminating at 585,000 lbs in 10,000 lbs increments. To model the "worst-case" scenario, a value of 35 knots was assumed for the average groundspeed during the taxi maneuver. C-17 regulations stipulate a maximum taxi speed of 40 knots.

The average fuel flow per operational engine model approximated average fuel flows per operational engine required to produce capable taxi thrust given incremental aircraft GWs and a 35-knot average taxi groundspeed. The results of this model were incorporated as a variable in the average engine pressure ratio per operational engine model.

To determine the average engine pressure ratio per operational engine, the following parameters were assumed: 1.6 miles for the total taxi distance, $200 \mathrm{~s}$ for the total taxi time, incremental aircraft GWs starting at 285,000 lbs and terminating at 585,000 lbs and an average aircraft groundspeed of 35 knots. Given the assumed parameters, the simplified average engine pressure ratio per operational engine model approximated average engine pressure ratios for each incremental setting of aircraft GW. Two iterations of calculations were executed: one baseline iteration for the four-engine taxi methodology and a second iteration for the twoengine taxi methodology.

\section{Analysis}

In contrast to theoretical fuel-savings models, the MFOQA data analysis accounts for variances in pilot taxi behaviors (i.e. aggressive thrust utilization and excessive braking). The data produces comprehensive results and estimates for the global C-17 mission set given varying environmental conditions and aircraft operating configurations. Initial results indicate that $\mathrm{C}-17 \mathrm{~s}$ can reduce fuel consumption and resource utilization by approximately

\begin{tabular}{lrr}
\hline Parameter & \multicolumn{1}{c}{ Coefficient } & $p$-value \\
\hline Time $\left(\alpha_{1}\right)$ & $4.87027 \mathrm{E}-06$ & 0.02230 \\
Distance $\left(\alpha_{3}\right)$ & -0.001417351 & 0.05074 \\
Groundspeed $\left(\alpha_{4}\right)$ & 0.000278939 & 0.00604 \\
Weight $\left(\alpha_{5}\right)$ & $6.32138 \mathrm{E}-09$ & 0.11017 \\
Inoperative engines $\left(\alpha_{6}\right)$ & 0.001033512 & 0.05989 \\
Fuel flow $\left(\alpha_{7}\right)$ & $1.31132 \mathrm{E}-05$ & $<0.001$ \\
Intercept $\left(\alpha_{8}\right)$ & 0.986734644 & $<0.001$ \\
\hline
\end{tabular}


$38.9 \%$ during the taxi phase per sortie if pilots perform reduced-engine taxi procedures instead of four-engine taxi procedures during surface operations before initial takeoff.

Figure 1 offers a comparison between the average fuel flows required per operational engine for four-engine and two-engine taxi methodologies given various locations, environmental conditions, pilot behaviors and aircraft configurations. The blue diamond data points represent the operational four-engine total fuel flow results. The orange square points represent the model's predictions for two-engine total fuel flow given the operational aircraft groundspeed, GW and number of inoperative engines. Figure 1 illustrates that the two-engine taxi methodology requires a higher fuel flow per operational engine to generate capable taxi thrust when compared to the four-engine taxi strategy.

Figure 2 highlights the individual data point comparison between the operational fourengine total fuel flow results and the linear model's predictive two-engine total fuel flow results. Once again, the blue diamond data points represent the operational four-engine total fuel flow
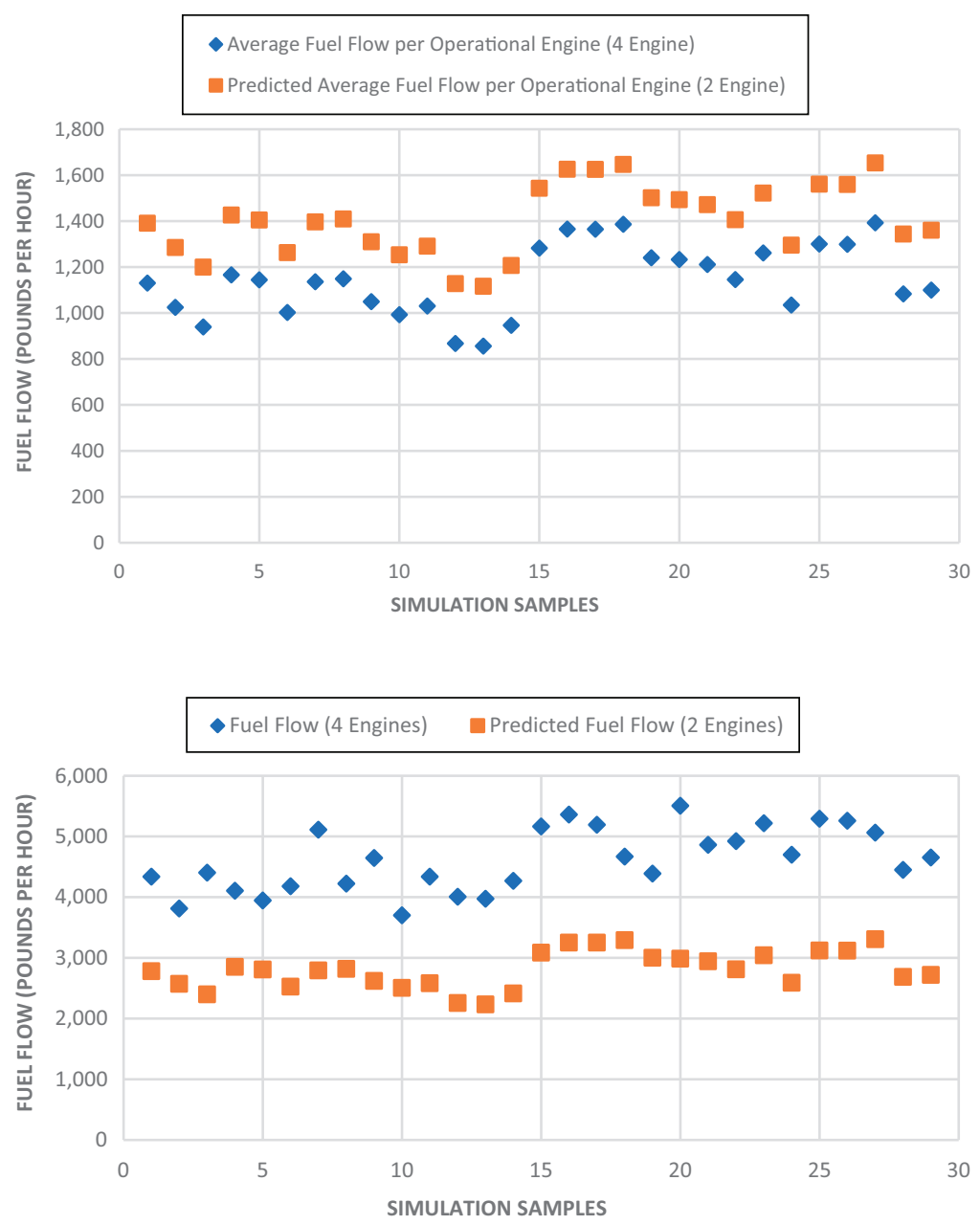

Modified C-17 taxi procedures

Figure 1.

Four-engine and twoengine (predicted) fuel flow per operational engine comparison
Figure 2.

Four-engine and twoengine (predicted) fuel flow comparison 
JDAL 4,2

results. The orange square points represent the model's predictions for two-engine total fuel flow given the operational aircraft groundspeed, GW and number of inoperative engines.

Figure 2 depicts the trends of the fuel burn for four-engine and two-engine taxi methodologies. This figure reveals that the reduced-engine taxi methodology consistently requires less total fuel consumption per hour than the four-engine taxi methodology. The comparison between Figure 1 and Figure 2 demonstrates that while greater fuel flow is required per individual engine in the reduced-engine taxi methodology, less fuel flow is used across the aggregate number of engines when using the proposed reduced-engine taxi strategy.

Table 4 depicts the comparative fuel and cost savings produced by reduced-engine taxi procedures in pounds of jet fuel per hour, gallons of jet fuel per hour and cost per hour. The Defense Logistics Agency published a price point of $\$ 2.26$ per gallon that was used for the cost calculation (Defense Logistics Agency, 2017). The data reveals that the MAF can save approximately $\$ 609.14$ per hour of C-17 surface maneuver by adopting the reduced-engine taxi methodology.

Boeing estimated a total fuel flow of 3,944 lbs per hour when using a four-engine taxi methodology (McCollum, 2017). Operational results from the analyzed data illustrate a total fuel flow average of 4,612.7 lbs per hour. These results demonstrate a discrepancy of 668.7 lbs per hour between the two methodologies. However, for the two-engine methodology, the mathematical model and Boeing's predicted fuel flow differ by only $18.4 \mathrm{lbs}$ per hour (i.e. a predicted model estimate of 2,806.0 lbs per hour versus a Boeing estimate of 2,788 lbs per hour). Despite the preferred methodology, notable fuel and cost savings are observed through the execution of a two-engine taxi strategy instead of a four-engine strategy.

\section{Results of cost savings simulation}

AMC/A9 reported that the MAF executed 52,195C-17 sorties in the fiscal year 2016. To estimate the anticipated fuel and cost savings available via the implementation of the reducedengine taxi procedure, this number was rounded down to 52,000 sorties. Maintenance data indicates that C-17s experience an average of 18 documented engine-start malfunctions per year. Including deficiencies discovered during inspections and encountered during flight, the C-17 fleet documented 583 engine issues during the year. These values illustrate negligible operational risk considering the volume of sorties executed by C-17s per year (i.e. less than a $1.2 \%$ risk of engine malfunctions per year). Assuming the "worst-case" scenario and considering potential risks presented by other system abnormalities, a highly conservative $2 \%$ operational risk factor was used in the cost savings simulation.

Table 5 illustrates the cost savings simulation's output of operational risks for 2,000 sorties to 52,000 sorties in increments of 2,000 sorties. Each row indicates the simulation's expected outputs of operational risk penalties in terms of pounds of fuel, gallons of fuel and costs in dollars per 2,000 sortie iteration. The aggregate of each column is annotated at the bottom of the table to demonstrate the predicted annual savings. If $2 \%$ of all sorties experience engine-start malfunctions and are required to return to parking from the furthest point of travel, then the operational risk penalty would equal approximately $\$ 70,364$ per year in fuel costs. Again, this is a high-side estimate.

Table 4.

Four-engine versus two-engine taxi savings comparison

\begin{tabular}{lccc}
\hline Taxi method & Fuel flow (£ per hour) & Fuel flow (gallons per hour) & Cost per hour (\$ per hour) \\
\hline Four-engine taxi & $4,612.70$ & 688.46 & $\$ 1,556$ \\
Two-engine taxi & $2,806.04$ & 418.81 & $\$ 947$ \\
Difference & $1,806.65$ & 269.65 & $\$ 609$ \\
\hline
\end{tabular}


Table 6 displays the potential cost savings for 2,000 sorties to 52,000 sorties in increments of 2,000 sorties. The fuel data for each row showcases the simulation's output per 2,000-sortie increment. The cost column demonstrates the cumulative benefit of cost savings in terms of dollars via the employment of the two-engine taxi methodology. The cumulative fuel savings in terms of pounds of fuel and gallons of fuel are found by summing the data in the respective columns. Assuming a Defense Logistics Agency prescribed $\$ 2.26$ price point per gallon of fuel (Defense Logistics Agency, 2017), the simulation reveals that reduced-engine taxi procedures have the capacity to save 1,178,590 gallons of fuel per year ( $\$ 2,663,613$ in annual fuel costs).

Figure 3 demonstrates the cumulative savings available via the employment of the reducedengine taxi procedure. The demonstrated relationship between C-17 sorties flown and cumulative savings in dollars exhibits linear behavior. With an $R^{2}$ value of 0.993 , the model

\begin{tabular}{lccc}
\hline No. of C-17 sorties & $\begin{array}{c}\text { Operational risk penalty } \\
\text { (£ of fuel) }\end{array}$ & $\begin{array}{c}\text { Operational risk penalty } \\
\text { (gallons of Fuel) }\end{array}$ & $\begin{array}{c}\text { Operational risk penalty } \\
\text { (cost in } \$ \text { ) }\end{array}$ \\
\hline 2,000 & $7,719.93$ & $1,152.23$ & $\$ 2,604$ \\
4,000 & $9,367.24$ & $1,398.10$ & $\$ 3,160$ \\
6,000 & $7,874.21$ & $1,175.25$ & $\$ 2,656$ \\
$\ldots$ & $\ldots$ & $\ldots$ & $\ldots$ \\
52,000 & $7,796.61$ & $1,163.67$ & $\$ 2,630$ \\
Total & $208,600.53$ & $31,134.41$ & $\$ 70,364$
\end{tabular}

Modified C-17 taxi procedures

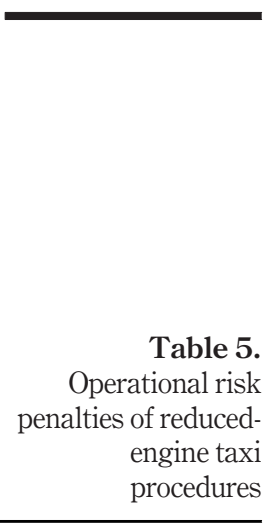

Table 6.

Total fuel and cost savings produced by the comparison of four-engine and reduced-engine taxi procedures per number of C-17 sorties

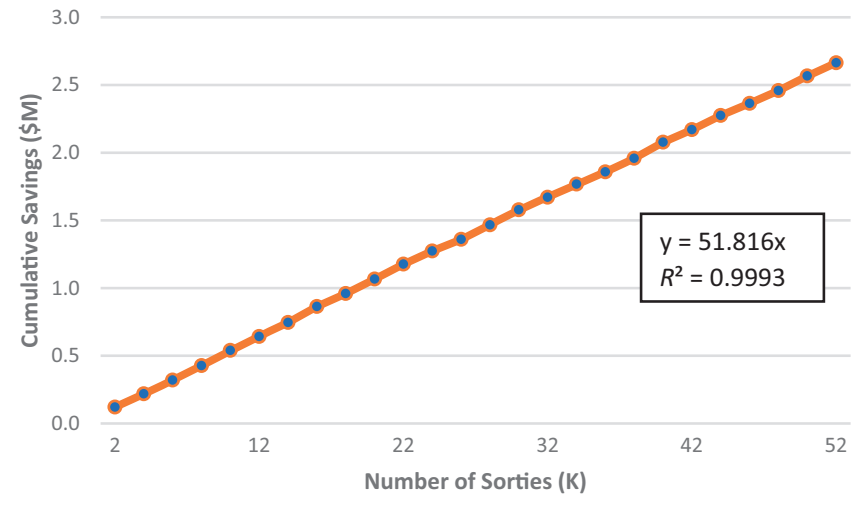

Figure 3. Cumulative savings (\$) vs the number of sorties 
JDAL

4,2

142

predicts that on average the MAF can save approximately $\$ 51.82$ in-ground fuel consumption costs per C-17 sortie that uses reduced-engine taxi procedures prior to initial takeoff.

To output higher fidelity savings values, the simulation can be edited to account for seasonal adjustments in aircraft GWs and refined total taxi time data based on expected operating locations. Additional savings are available if pilots use the reduced-engine taxi procedures on a more routine basis than the $50 \%$ employment prediction. Implementation of the reduced-taxi procedures has the ability to save millions of dollars for the USAF.

\section{Results of optimal taxi policy model}

The optimal taxi policy prescribes either a four-engine or two-engine taxi strategy based on aircraft GW and mitigation of risk caused by the excessive jet blast (as defined by the aircraft's engine pressure ratio). The optimal taxi policy model averages variances in pilot taxi behaviors, environmental conditions and aircraft configurations to create an approximated average engine pressure ratio per operational engine throughout the duration of the taxi maneuver. The results reveal that the two-engine taxi methodology has the capability to produce maneuverable taxi thrust for all aircraft GWs (up to and including the maximum C-17 GW of 585,000 lbs) without exceeding the assigned maximum average limit of 1.03 engine pressure ratio.

The average standard error between the engine pressure ratio outputted by the optimal taxi policy model and the operational results was $7.2 \%$. The average standard error between the model and the operational results for the operational three-engine taxi data was $8.8 \%$. These standard errors illustrate an acceptable trend between operational and predicted and lend toward acceptable confidence in the two-engine extrapolation. Figure 4 illustrates the comparison between the optimal taxi policy model and operational engine pressure ratios per data sample.

Figure 5 illustrates the average engine pressure ratio expected per operational engine according to aircraft $\mathrm{GW}$ when using reduced-engine taxi procedures. The data demonstrates that the correlation between aircraft GW and average engine pressure ratio is linear. As aircraft $\mathrm{GW}$ increases, the thrust required to produce capable taxi thrust increases proportionately by a constant of 3.3703E-8. This model yields a perfect $R^{2}$ value of 1.0 (i.e. a direct correlation).

Given a C-17 loaded to a maximum $\mathrm{GW}$ of $585,000 \mathrm{lbs}$, the average expected engine pressure ratio to produce capable taxi thrust was calculated as 1.0289. The experimental design illustrates that a lightweight C-17 $(285,000 \mathrm{lbs})$ required an average engine pressure ratio per operational engine of 1.0188 . These results establish that the average difference in

Figure 4.

Comparison of model vs operational engine pressure ratios per data point

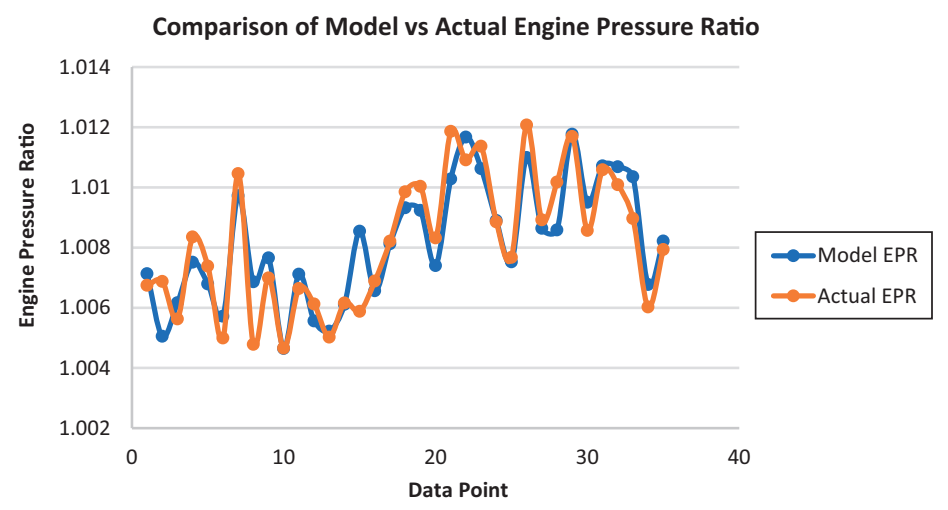




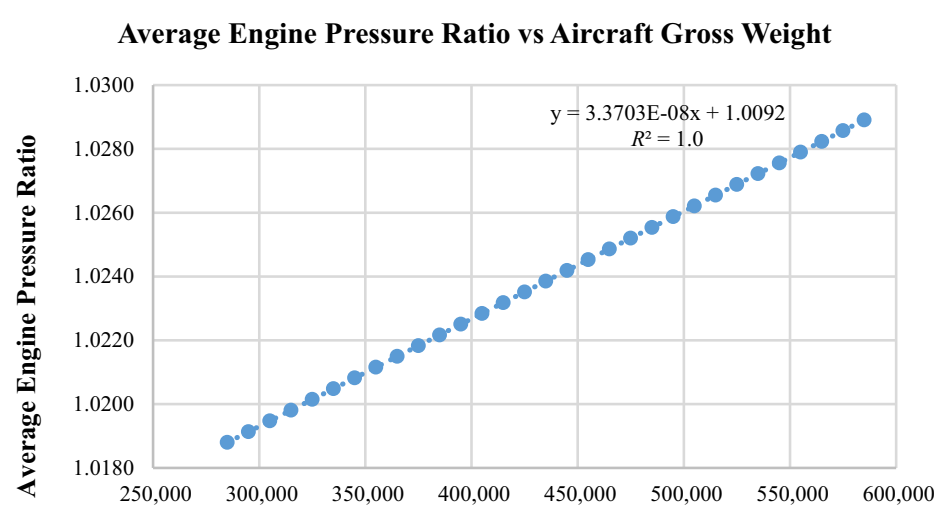

Aircraft Gross Weight (Pounds)

- Model Ave Engine Pressure Ratio ...... Linear (Model Ave Engine Pressure Ratio)
Modified C-17

taxi

procedures

143

engine pressure ratio to maneuver a lightweight $\mathrm{C}-17$ and a maximum $\mathrm{GW} \mathrm{C}-17$ is approximately 0.0101 engine pressure ratio.

Temporary aircraft stops and delays along the route of taxi decrease the average engine pressure ratio, as the engine remains at idle thrust for the duration of the delay. The engine pressure ratio required for breakaway thrust from a stopped position is typically higher than the taxi average. Engines intended for a taxi should have sufficient time to properly warm-up prior to initiation of a taxi while pilots complete their "before taxi" checklists. If additional engines are started during the route of taxi, a maximum engine pressure ratio limit may be necessary to minimize engine wear.

Of note, current regulations do not specify an engine pressure ratio limit for C-17 engines on the initial taxi out. Analysis of the provided MFOQA data reveals that pilots used engine pressure ratios up to 1.129 on the initial taxi out. Of the data samples analyzed, an average maximum of 1.06 engine pressure ratio was observed.

Reduced-engine taxi procedures have the potential to yield significant savings for the USAF. The MAF can reduce fuel consumption and resource utilization by approximately $38.9 \%$ during the taxi phase per sortie if pilots perform reduced-engine taxi procedures instead of four-engine taxi procedures during surface operations before initial takeoff. The cost savings simulation revealed that reduced-engine taxi procedures have the capacity to save $1,178,590$ gallons of fuel per year ( $\$ 2,663,613$ in annual fuel costs). Finally, the twoengine taxi methodology has the capability to produce maneuverable taxi thrust for all aircraft GWs (up to and including the maximum C- $17 \mathrm{GW}$ of 585,000 lbs) without exceeding the assigned average limit of 1.03 engine pressure ratio.

\section{Limitations and recommendations for future research}

This research explored the viability of $\mathrm{C}-17$ reduced-engine taxi procedures from a cost saving and risk perspective. This project did not consider any potential second or thirdorder effects of reduced-engine taxi procedures. Future research could seek out and examine any such effects. The suggested research would generate a better understanding of potential limitations unique to USAF operations and allow for individualized tailoring of the strategy to match operational requirements and needs. 
JDAL 4,2

This research focused on the fuel and cost savings associated with C-17 reduced-engine taxi operations. AMC can implement this taxi strategy across the MAF community with airframedependent operational caveats that demand comprehensive investigation and research. For instance, air refueling platforms such as the KC-135 and KC-10 possess unique operational requirements that mandate the engine starts at specific times prior to takeoff. Future analysis and exploration of these aircrafts' engine capabilities are required to determine the feasibility of reduced-engine taxi employment in their respective communities.

Once implemented through operational checklist updates, reduced-engine taxi procedures will become second-nature for pilots who practice the methodology. This research assumes young crews have the ability to effectively delegate duties and one pilot can start an engine while the second pilot executes the taxi maneuver. Future analysis and experimentation can be conducted in a simulated environment to test and evaluate the capacity of crew members to safely perform this new procedure.

\section{Conclusions}

This study demonstrates that reduced-engine taxi procedures have the potential to generate capable taxi thrust for $\mathrm{C}-17 \mathrm{~s}$ regardless of aircraft $\mathrm{GW}$. From a fiscal perspective, significant fuel and costs savings are available via optimized taxi procedures. These results indicate that current MAF taxi strategies have the capacity to optimize resource utilization and explore efficiencies. The results suggest that AMC should:

- Evaluate the feasibility of reworking the C-17 consolidated checklist and flight manuals.

- Install an incremental fleet-wide training and qualification program.

- Evaluate future aircraft recapitalization requirements to cater toward the employment of fuel savings during ground movements.

\section{References}

Air Mobility Command (2015), "AMC pamphlet 11-3, birds fly free, AMC doesn't: an aircrew guide for efficient fuel use", available at: http://static.e-publishing.af.mil/production/1/amc/publication/ amcpam11-3/amcpam11-3.pdf (accessed 25 October 2019).

Brown, M. (2011), Supporting Aviation Fuel Efficiency with Lessons Learned so Far, Air Force Comptroller.

Davis, G.F. and Cobb, A. (2010), "Chapter 2 resource dependence theory: past and future", in Bird Schoonhoven, C. and Dobbin, F. (Eds), Stanford's Organization Theory Renaissance, 1970-2000 (Research in the Sociology of Organizations), Emerald Group Publishing Limited, Bingley, Vol. 28, pp. 21-42, doi: 10.1108/S0733-558X(2010)0000028006.

Defense Logistics Agency (2017), "Standard prices", available at: www.dla.mil/Energy/Business/ StandardPrices/ (accessed 3 February 2017).

Dept of Defense (2012), "Sustaining US global leadership: priorities for 21st-century defense", available at: http://archive.defense.gov/news/defense_strategic_guidance.pdf (accessed 8 December 2018).

Dept of the Air Force (2011), "AFI 11-2C-17v3, C-17 operations procedures", p.179, available at: www. bits.de/NRANEU/others/END-Archive/AFI11-2C-17V3(11).pdf (accessed 25 October 2019).

Donley, M.B. and Welsh, M.A. (2013), “US air force energy strategic plan”, available at: http://fedne.ws/ uploads/afenergy_fnr.pdf (accessed 8 December 2018).

Hillman, A.J., Withers, M.C. and Collins, B.J. (2009), "Resource dependence theory: a review”, Journal of Management, Vol. 35 No. 6, pp. 1404-1427, doi: 10.1177/0149206309343469. 
Joyner, B. (2011), "Fuel-efficient", Citizen Airman, April, pp. 14-17.

Modified C-17

Kennedy, M., Baldwin, L.H., Boito, M., Calef, K.M., Chow, J.S., Cornuet, J., Eisman, M., Fitzmartin, C., Gebman, J.R., Ghashghai, E., Hagen, J., Hamilton, T., Hildebrandt, G.G., Kim, Y., Leonard, R.S., Lewis, R., Loredo, E.N., Norton, D.M., Orletsky, D.T., Perdue, H.S., Pyles, R.A., Roll, C.R., Jr, Stanley, W., Stillion, J., Timson, F. and Tonkinson, J. (2006), Analysis of Alternatives (AoA) for KC-135 Recapitalization: Executive Summary, Rand Corporation, doi: 10.7249/MG495.

Khadilkar, H. and Balakrishnan, H. (2011), "Estimation of aircraft taxi-out fuel burn using flight data recorder archives", AIAA Guidance, Navigation, and Control Conference, Portland OR, doi:10.2514/6.2011-6383.

Koudis, G.S., Hu, S.J., Majumdar, W.Y., Ochieng, M.E. and Stettler, E.J. (2018), "The impact of singleengine taxiing on aircraft fuel consumption and pollutant emissions", The Aeronautical Journal, Vol. 122 No. 1258, pp. 1-18, doi: 10.1017/aer.2018.117.

Marais, K.B., Reynolds, T.G., Uday, P., Muller, D., Lovegren, J., Dumont, J. and Hansman, R.J. (2013), "Evaluation of potential near-term operational changes to mitigate environmental impacts of aviation", Proceedings of the Institution of Mechanical Engineers, Part G: Journal of Aerospace Engineering, Vol. 227 No. 8, pp. 1277-1299, doi: 10.1177/0954410012454095.

McCollum, P. (2017), Boeing Interview, Unpublished.

Mouton, C.A. Powers, J.D. Romano, D.M. Guo, C. Bednarz, S. and O'Connell, C. (2015), "RAND project air force, fuel reduction for the mobility air forces", available at: www.rand.org/t/RR757 (accessed 8 December 2018).

Nienhüser, W. (2008), "Resource dependence theory - how well does it explain behavior of organizations?", Management Revu, Vol. 19 Nos 1/2, pp. 9-32, doi: 10.5771/0935-9915-2008-1-2-9.

Schumacher, M. (2015), "C-17 aircraft ommander fuel efficiency metrics and goal evaluation”, Master's Thesis, Air Force Institute of Technology.

Schwartz, M. Blakeley, K. and O'Rourke, R. (2012), "Department of defense energy initiatives: background and issues for congress", Library of Congress. Congressional Research Service, available at: https:// digital.library.unt.edu/ark:/67531/metadc491036/(accessed 8 December 2018).

Secretary of the Air Force for Installations, Environment, and Energy (2016), "United States air force energy task force, reduced engine taxi analysis".

United States Air Force Energy Analysis Task Force (2018), “United States Air Force Energy Task Force, Reduced Engine Taxi Analysis".

\section{Corresponding author}

Michael Kretser can be contacted at: michaelpk1@gmail.com

For instructions on how to order reprints of this article, please visit our website:

www.emeraldgrouppublishing.com/licensing/reprints.htm

Or contact us for further details: permissions@emeraldinsight.com 